\title{
Excessive Internet Use and Its Hours Usage Control among Indonesian Students in China
}

\author{
Wulan Patria Saroinsong, Xiao Jun Sun, Chinun \\ Boonrungrut \\ School of Psychology \\ Central China Normal University \\ Wuhan, China \\ wulanpatria@mail.ccnu.edu.cn \\ Mochamad Nursalim \\ Department of Counseling and Guidance \\ Universitas Negeri Surabaya \\ Surabaya, Indonesia
}

\author{
Brwa Aziz Sidiq \\ School of Foreign Language \\ Central China Normal University \\ Wuhan, China \\ Wagino \\ Department of Special Education \\ Universitas Negeri Surabaya \\ Surabaya, Indonesia
}

\author{
Nurhenti Dorlina Simatupang \\ Department of Early Childhood Education \\ Universitas Negeri Surabaya \\ Surabaya, Indonesia
}

\begin{abstract}
At one decade, the internet has changed human lifestyles, and it harms daily student life. The adverse effects including physically and mentally problem had decreased student social skill and coping styles on real life. The aims of these studies were to explore the predictions of Internet hour usage on Indonesian student internet excessive use. Indonesian students in Wuhan have been participating in this study. This study using quantitative approached using descriptive statistic. The main finding revealed, regarding the daily internet use, comparison among Indonesian on internet addiction level have the difference which is Indonesian students using the Internet from less than 1hour until more than 12 hours per day otherwise students no one uses the Internet less than 1 hour. The data above revealed internet addiction level on Indonesian could be described based on daily internet usage. Therefore, daily internet usage could predict the Indonesian level addiction on the Internet. Otherwise, it could not be applied to the students, whereas Indonesian students on the daily usage have higher Internet addictive level than Chinese students.
\end{abstract}

Keywords - internet excessive use; internet hour usage

\section{INTRODUCTION}

In the globalization era, human needs have been changed within the technology growth rapidly. Five needs of human seem pyramid shapes such as primary, love, safety, self-esteem, and self-actualization needs [1]. The fifth need would be fulfilled whether the basic needs completed or not. Eat, drink, sleep, and sex, as the basic needs should be fulfilled, then people would be satisfied regarding the four needs.

Nowadays, self -actualization, and self-esteem have been replaced the basic needs become the basic needs as a lifestyle to explore their feeling and expression for getting happiness in their life. It leads the people to use the technology tools as a mediator to reach it.
In the seventh recent years, most of the people who have experienced some of the various benefits of internet networks, with the rapid growth and prevalence of internet network technology $[2,3]$. For example, on the Internet, people can find specific information, talk with others, and purchase almost any kind of merchandise. On this case, young people are generally viewed as the majority of Internet users.

Currently, the Internet is the most important thing in human life [4-6]. Everyday people need it to support their work, study, business, and relationship. The total number of worldwide internet users worldwide from 2005 to 2018 was 3.9 billion and January 2019 as of the measured period, almost 4.4 billion people were active internet users, and 3.5 billion were social media users [7]. Principally, Asia has the highest number of Internet users in the world, approximately 922.3 million, representing 44\% share of the world's Internet user population, according to data by Internet World Stats. In Asia, there has been a growing concern on what has been labeled "Internet addiction." It has to present as a severe public health issue in certain Asian countries [8]. In Beijing, a leading judge said that $90 \%$ of juvenile crime in Beijing city was Internet-related [9]. Besides, According to Ministry of Health, staying online more than six hours a day and having adverse reactions from not being able to go online, are symptoms of Internet addiction disorder [10].

According to the government, 802 million people are now actively using the Internet, 57.7 percent of the population [11], which is a branch of the country's Ministry of Industry and Information [12]. In additional compare within Indonesian Internet users, 2018 had been reaching 132.7 million of 265.4 million populations or $50 \%$ penetration on the Internet. China and Indonesia are the top 10 ranks in the full world and the Asia Pacific as Internet users. In the world, Indonesian is the fifth 
rank meanwhile in the Asia-Pacific, placed in the same rank and Indonesian third ranks.

The Internet has a positive and negative impact on human life, and people would get the benefit from the internet whether they use correctly suitable with their needs not solely their desire. People would become dependent on the internet with the excessive to use the internet. Addiction is a negative impact on the internet that could lead people to have both physical as well as the psychological problem. An individual might face behavioral problem due to over usage of the internet where they are reacting differently than the normal behavior $[13,14]$. Some other physical problems might occur due to the extended use of the Internet. Some physical problems are migraine or headache, sleep pattern disrupts [15-17].

Internet addiction, some experts [18-21] defined that a person has an excessive desire to spend much time on the Internet. It is figuring out the other areas of life (such as relationships, work, or health) are intend to suffer. Internet dependence has needs to spend more time online to achieve the same desire. Medical opinion divided on whether Internet addiction exists as a mental disorder in its own right or whether it is an expression of preexisting mental disorders or behavioral problems. For instance, a person who compulsively trawls the Internet for online gambling venues may have a gambling problem rather than an Internet addiction.

Internet addiction becomes a general mental illness that states in DSM-V [22]. Conceptually, compulsive-impulsive spectrum disorder diagnosis that involves online and offline computer usage. It has three subtypes: excessive gaming, sexual preoccupations, and e-mail/text messaging.

The variants of symptoms share the following four components: 1) excessive use on the internet, frequently related unconscious or basic needs 2) withdrawal, including anger, tension, and depression when the computer is disconnected, 3) tolerance, need for high-speed connection and computer equipment, more software, or more hours of use, and 4) negative repercussions, which is having arguments, lying, poor achievement, social isolation, and fatigue.

In a comparison study in Indonesia, the estimated online game addictions cases are $(10.15 \%)$ among Indonesian school students that currently played online games are quite alarming. In comparison, Korea estimated $2.4 \%$ game addiction cases and $10.2 \%$ or parents as more punitive and aged 9 to 39 years old, and China estimated $13.7 \%$ of adolescent internet uses to meet the internet addiction diagnostic criteria. Meanwhile, data from the United States and Europe showed an estimate of $1.5 \%$ to $8.2 \%$ of internet addiction cases [18].

At first sight, the estimated percentage of Indonesian online game addiction cases is comparable to other countries [24,25] However, it must be noted that the Indonesian data is highly specific to online games, whereas data from other countries have a broader scope. The data from Korea showed game addiction, which includes both, online and non-online gamers. Whereas, the data from China, the United States, and Europe showed internet addiction, which includes a more extensive range of activities, such as chatting, browsing, and online games.
Therefore, Indonesia has comparable estimated prevalence with other countries.

Hypothesis:

1) Male has internet addiction level higher than female between Indonesia Student in Wuhan

2) Bachelor student has internet addiction level higher than master and doctorate Student between Indonesia student in Wuhan

3) Human and arts Major has higher Internet addiction level than math and science among Indonesian colleges in Wuhan

4) The ages between 18-22 has internet addiction level higher than others ages among Indonesian colleges in Wuhan

5) SIU has internet addiction level greater than addiction GIU among Indonesian colleges in Wuhan

6) Hours usage on internet, predict the Internet addictive level among Indonesian colleges in Wuhan.

\section{METHOD}

The recent study showed the relationship and predictions of demographic information to Internet hour usage and excessive internet use. The model elaborated as following:

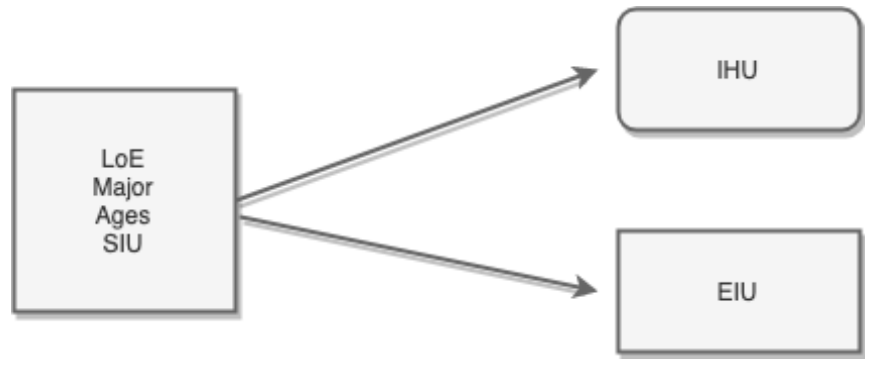

Fig. 1. Design of study

Note: LoE : Level of Education; SIU :Specific Internet Use; IHU: Internet Hours Usage, EIU: Excessive Internet Use

Recent study has took using randomized sampling; Indonesian participants are colleges in Wuhan, divided into some of universities. Total number of Indonesian student in Wuhan, around 190 students. Additionally, the students' will come from a variety of cultural backgrounds such as parenting, behavior, and perception, etc. Another thing, education level, major and gender.

Quantitative Approach using Descriptive statistic and inferential-parametric analysis particularly had been applied to obtained and examine the independent variable, dependent variable and moderator variable. In additional the scale within strong validity and acceptable reliability had use to measure the endogenous and exogenous variable in the cross-sectional study.

Recent study, aims to obtained the difference of internet addiction base on the demographic information, it used t-test and one-way ANOVA analysis. In addition, to examine the hour usage in internet can be predicting internet addiction level, it will use regression analysis. 


\section{RESULTS AND DISCUSSION}

Descriptive statistical analysis aims to describe data that have been collected. Commonly used descriptive statistics include frequency counts, ranges (high and low scores or values), means, modes, median scores, and standard deviations. [26] The recent study purposed to describe the demographic variables, independent, and dependent variables. It would present as following.

TABLE I. DEMOGRAPHIC INFORMATION

\begin{tabular}{|c|c|c|c|}
\hline \multirow[t]{2}{*}{ Variables } & & \multicolumn{2}{|c|}{ Indonesian $(N=175)$} \\
\hline & & $n$ & $\%$ \\
\hline Daily internet & $<1$ hour & & \\
\hline \multirow[t]{4}{*}{ Use } & 1-4 hours & 6 & 2.9 \\
\hline & 5-8 hours & 78 & 44.9 \\
\hline & $9-12$ hours & 60 & 34.3 \\
\hline & $>12$ hours & 31 & 18.1 \\
\hline Education & Undergraduate & 41 & 23.3 \\
\hline \multirow[t]{2}{*}{ Level } & Master & 61 & 34.9 \\
\hline & Doctor & 73 & 41.8 \\
\hline \multirow[t]{2}{*}{ Major } & Art \& Humanity & 146 & 83.7 \\
\hline & Math \& Science & 29 & 16.3 \\
\hline \multirow[t]{2}{*}{ Gender } & Male & 81 & 45.90 \\
\hline & Female & 94 & 54.1 \\
\hline \multirow[t]{3}{*}{ Age } & $18-21$ & 49 & 27.9 \\
\hline & $22-27$ & 62 & 35.5 \\
\hline & $>27$ & 64 & 36.5 \\
\hline Kinds of & Social Media $^{\mathrm{a}}$ & 80 & 45.7 \\
\hline \multirow[t]{2}{*}{ Websites } & Search engine ${ }^{b}$ & 75 & 42.8 \\
\hline & Microblog $^{c}$ & 20 & 11.4 \\
\hline \multirow{2}{*}{$\begin{array}{l}\text { Proposes of } \\
\text { Online }\end{array}$} & Study $^{\mathrm{d}}$ & 34 & 19.4 \\
\hline & Working/Business ${ }^{\mathrm{e}}$ & 49 & 28.1 \\
\hline Activities & Entertainment $^{\mathrm{f}}$ & 92 & 52.5 \\
\hline \multirow[t]{2}{*}{ Drinking } & No & 150 & 85.5 \\
\hline & Yes & 25 & 14.5 \\
\hline \multirow[t]{2}{*}{ Smoking } & No & 154 & 87.8 \\
\hline & Yes & 21 & 12.2 \\
\hline
\end{tabular}

Note:

a; Facebook, WeChat, Skype, Baidu, YouTube, QQ Messenger, Line and Instagram,

b; Google, Baidu, QQ,

c; WB, Twitter,

d; each Articles, books, information,

e; Search Information, chatting, calling, upload video, picture business,

f; Chatting, calling, upload picture, watch video, gaming for relaxing,

Indonesian students use social media such as Facebook, WeChat, Instagram and YouTube. Regarding the online activity $26.2 \%$ student's use Internet to entertained their self-such as, chatting, calling, picture uploading, watch movie and gaming. By the special website which is (online shop, porn site, game $10.9 \%$.

TABLE II. MEAN, SD INTERNET USAGE

\begin{tabular}{clcc}
\hline Variables & & \multicolumn{2}{c}{ Indonesian } \\
\cline { 3 - 4 } & & $\boldsymbol{M}$ & $\boldsymbol{S D}$ \\
\hline Daily internet & $<$ 1hour & 39.4 & 11.1 \\
Use & 1-4 hours & 44.9 & 13.4 \\
& 5-8 hours & 45.2 & 12.6 \\
& 9-12 hours & 50.3 & 13.9 \\
Education & $>$ 12 hours & 50.6 & 13.3 \\
Level & Undergraduate & 44.9 & 10.3 \\
& Master & 45.5 & 14.9
\end{tabular}

\begin{tabular}{clcc}
\multirow{3}{*}{ Major } & Doctor & 46.9 & 12.9 \\
& Art \&Social & 56.5 & 13.2 \\
& Humanistic & & \\
\multirow{3}{*}{ Gender } & Math\& Science & 55.7 & 13.8 \\
& Male & 47.8 & 13.5 \\
& Female & 45.2 & 13.03
\end{tabular}

Regarding the daily internet use, Indonesian on internet addiction level have is $<1$ hour until $>12$ hours per day. The data above revealed Internet addiction level on Indonesian could be described based on the daily internet usage. It shows long hours engaged on internet the mean score of internet addictive level gradually increase as well. In addition, internet addictive level with the mean score \pm 60.04 placed on the 1-4-hour usage and more hour usage gradually decrease the internet addictive level. Therefore, daily internet usage could be predicted the Indonesian level addiction on internet.

\begin{tabular}{|c|c|c|c|c|c|c|c|c|}
\hline TABLE III. & MAIN & $\begin{array}{l}\text { FFECT } \\
\text { IN }\end{array}$ & $\begin{array}{l}\text { INTERN } \\
\text { RNET SC }\end{array}$ & $\begin{array}{l}\Gamma \text { ADDI } \\
\text { RE }\end{array}$ & ON ON & ILY & SAGE & \\
\hline \multirow{2}{*}{$\begin{array}{c}\text { Dependent } \\
\text { Variable } \\
\end{array}$} & \multicolumn{5}{|c|}{$\begin{array}{l}\text { Spent hours M (SD) } \\
\text { (INDO) }\end{array}$} & \multirow[t]{2}{*}{$\mathbf{F}$} & \multirow[t]{2}{*}{$\eta_{p}^{2}$} & \multirow[t]{2}{*}{$\mathbf{P}$} \\
\hline & $<1$ & $1-4$ & $5-8$ & $9-12$ & $>12$ & & & \\
\hline Internet & 43.8 & 46.9 & 46.8 & 44.3 & 47.3 & 18 & .84 & . \\
\hline \multirow[t]{2}{*}{ Addiction } & (12.9) & (12.3) & (14.4) & (12.8) & (14.5) & 88 & & 0 \\
\hline & & & & & & 1.7 & & 0 \\
\hline
\end{tabular}

The first MANOVA Table compares the main effect of 154 participant's score on Internet daily hour usage. A main effect was detected the significance coefficient (Pillasi's Trace = $0.965, \mathrm{~F}=3122, p .<0.001$, multivariate $\eta 2=0.965)$. It means spent hours have contribute on excessive use of internet.

Regarding the daily internet use, comparison among Indonesian on internet addiction level have the difference which is Indonesian students using the Internet from $<1$ hour until $>12$ hours per day otherwise students no one uses the Internet less than 1 hour. The data above revealed Internet addiction level on Indonesian could be described based on daily internet usage. It shows long hours engaged on the Internet the mean score of addictive internet level gradually increases as well. In the new Internet, addictive level with the mean score \pm 60.04 placed on the 1-4 hours' usage and more hour usage gradually decrease the addictive internet level. Therefore, daily internet usage could predict the Indonesian level addiction on the Internet. Otherwise, it could not be applied to the students, whereas students on the daily usage 1-4 hours have higher Internet addictive level $( \pm 60.04)$ than Indonesian students $( \pm 44.9)$.

Regarding the education level on Internet addictive, revealed that the Doctor internet addictive level higher than undergraduate as well as master students among Indonesian.

In new Internet, addictive level based on the significant students revealed that Indonesian students have mean score \pm 56.5 on internet addiction level based on the Art and Social Humanistic Significant. It describes major could be the factors to increase the internet addiction level on both of students. Moreover, Indonesian male students have mean \pm 47.8 as well as Female students among Indonesian.

Internet users were not only the world's most numerous in 2011 , they also spent an average of nearly $1000 \mathrm{~h}$ each on the 
Internet that year [27]. That is, Internet users were online an average of $18.7 \mathrm{~h}$ a week, an increase of nearly a half hour compared [12]. The rates approximately 513 million used the Internet in 2011, with comparatively high levels of use. Whereas the number of studies (reviewed herein) determines that Internet Addiction is endemic among youth and prevalence upward, no prior review has examined family correlates of youth Internet addiction

There is an attempt to shed some light on how internet users in Indonesia who perceive they are heavy users on the Internet [28]. It interprets the internet addiction meaning. It is a phenomenological study based on interviews with nine informants who see themselves as internet addicts. This study showed that the informants spend 1 to 8 hours daily to access the Internet, and they feel upset, angry, bored, outcast, disconnected from the world, or feel like something is missing when they are unable to connect with the Internet, (6) the informants have their commitment in the workplace. Meanwhile, the informants do not consider their internet addiction as urgently. Rather than, they see their 'addiction' as part of their daily needs and lifestyle.

This study implicated in the daily hours use that can increase the overuse on the Internet. Controlled on internet use hours could defeat the excessiveness on Internet. In other hands the education level implied the internet usage on Indonesian students, it proves that on using internet doctoral students more intentional using the Internet in order to find the recourses of journals, information, and e-books to support their research. Moreover, lifestyle, particularly in the study, leads students to use the Internet excessively.

\section{CONCLUSION}

In recent years, the Internet is an essential thing in human life. Everyday people need it to support their work, study, business, and relationship. It replaces the basic needs in human life as Maslow pyramid theory [29]. the total number of worldwide Internet users worldwide from 2005 to 2018 was 3.9 billion [7] and January 2019, as of the measured period, approximately 4.4 billion people have active on the Internet either 3.5 billion were social media users.

Generally, Asia has the highest number of Internet users in the world, approximately 922.3 million, representing $44 \%$ share of the world's Internet user population, according to data by Internet World Stats [30]. In Asia, there has been a growing concern on what has labeled "Internet addiction." It has seen as a severe public health issue in certain Asian countries. In Beijing, Shan Xiuyun, a leading judge, has said that $90 \%$ of juvenile crime in the Beijing city was Internet-related. According to the Chinese Ministry of Health, staying online more than six hours a day and having adverse reactions fro

China and Indonesia had been the TOP 20 countries with the highest number of internet user [31], China has in the 1st level and follows by Indonesia at the 5th. The advance of mobile phone technology enables people to access the Internet quickly. Internet users do not have to make specific time to be able to access; they only need data or balance in the cell phone or WiFi.
The findings indicate that although the students consider their internet addiction is quite an issue, they are not qualified into mental disorder. The internet addiction that belongs to the students; it is the lifestyle due to make their life more comfortable in the study, work, and communication with friends and family. Young [30] qualified four significant points regarding Internet Addiction Disorder (IAD): 1) excessive use, (2) withdrawal, (3) tolerance, and (4) negative repercussions. In accordance with these four components, the participants probably overuse on internet from 1 to 8 hours, feel bored and upset when unable to connect with the Internet, need the highspeed internet connection, feel entertained and relax, and get the head pain, eye ache and back pain. It is all what the students feel when engaging with Internet. In the meantime, whether students realize their main priorities are the focus on study and working, it showed students might control themselves. Also, students could separate the real and virtual world, they realized regarding their own life between the offline and online world.

\section{REFERENCES}

[1] Society of Human Resource Managers. (2002, October 2). Technology and privacy use. Retrieved from http://www.shrm.org/trends/visions/default.asp?page=0300c.asp

[2] Associated Press. (2000, July 28). A Dow Chemical fires 50 over offensive e-mail. CNET News. Retrieved from http://news.cnet.com/news/0-1007-200-2372621.html

[3] H. R. Lesieur, S. B. Blume. (1993). Pathological gambling, eating disorders, and the psychoactive substance use disorders. Comorbidity of Addictive and Psychiatric Disorders, 9(1), 89-102.

[4] S. Levy. (1996, December 30/January 6). Breathing is also addictive. Newsweek, 128, 52-53.

[5] J. J. Block. Issues for DSM-V: Internet addiction. Am. J. Psych 165(3), 306-307 (2008).

[6] I. J. Bakken, H. G. Wenzel, K. G. Gotestam, et al. Internet addiction among Norwegian adults: A stratified probability sample study. Scand. J. Psychol 50(2), 121-127 (2009).

[7] K. Jetlund. "Improvements In Automated Derivation Of Owl Ontologies From Geospatial UML Models." International Archives of the Photogrammetry, Remote Sensing \& Spatial Information Sciences 42.4 (2018).

[8] Czincz, Jennifer, and R. Hechanova. "Internet addiction: Debating the diagnosis." Journal of Technology in Human Services 27.4 (2009): $257-$ 272 .

[9] R. Marr. "The modern abdominoperineal excision: the next challenge after total mesorectal excision." Annals of surgery 242.1 (2005): 74.

[10] D. Kardefelt-Winther. "A conceptual and methodological critique of internet addiction research: Towards a model of compensatory internet use." Computers in Human Behavior 31 (2014): 351-354.

[11] K. S. Young. (1999). The evaluation and treatment of Internet addiction. In L. VandeCreek \& T. Jackson (Eds.), Scherer, K. (1997, August). College life online: Healthy and unhealthy Internet use. Paper presented at the 104th Annual Meeting of the American Psychological Association, Chicago.

[12] T. Zhou. "Understanding mobile Internet continuance usage from the perspectives of UTAUT and flow." Information Development 27.3 (2011): 207-218

[13] A. Barber. (1997, March 11). Net's educational value questioned. USA Today, p. 4D. 
[14] K. Brady. (1996, April 21). Dropout rise a net result of computers. The Buffalo News, p. A1.

[15] L. A. Collins. (2000, July 27). A Dow Chemical fires 50 over e-mail. Retrieved from http://news.excite.com/news/ap/000727/18/dowchemical-e-mail

[16] B. M. Melnyk, E. Fineout-Overholt. (2011). Evidence-based practice in nursing and healthcare: A guide to best practice. $\left(2^{\text {nd }}\right.$ ed.).

[17] H. Rheingold. (1993). The virtual community: Homesteading on the electronic frontier.

[18] K. S. Young. (1998). Internet addiction: The emergence of a new clinica disorder. Cyber Psychology \& Behavior, 1, 237-244.

[19] K. S. Young. (1998). Caught in the Net: How to recognize the signs of Internet addiction and a winning strategy for recovery. New York: John Wiley.

[20] M. Shotton. (1991). The costs and benefits of "computer addiction." Behaviour and Information Technology, 10(3), 219-230

[21] F. Stewart. (2000). Internet acceptable use policies: Navigating the management, legal, and technical issues. Information Systems Security, 9(3), 46-53.

[22] American Psychiatric Association. Diagnostic and Statistical Manual of mental Disorders (DSM-5). Arlington, VA. American Psychiatric Association (2013)
[23] American Psychiatric Association. (1994). Diagnostic and statistical manual of mental disorders (4th ed.) Washington, DC: Author.

[24] American Psychological Association. (1980). Diagnostic and Statistical Manual of Mental Disorders (3rd ed.). Washington, DC: Author.

[25] S. Swanson. (2001). Beware: Employee monitoring is on the rise Information week, 851, 57-58.

[26] M. C. Murray. "Student interaction with online course content: Build it and they might come." Journal of Information Technology Education: Research 11 (2012): 125-140.

[27] Innovations in clinical practice: A source book (pp. 17, 19-31). Sarasota, FL: Professional Resource Press.

[28] American Psychological Association. (1987). Diagnostic and Statistical Manual of Mental Disorders (3rd end, rev.). Washington, DC: Author.

[29] American Psychological Association. (1994). Diagnostic and Statistical Manual of Mental Disorders (4th ed.). Washington, DC: Author.

[30] K. S. Young. (2003, August). Employee Internet management: Current business practices and outcomes. Paper presented at the Annual Meeting of the American Psychological Association, Toronto, Ontario, Canada.

[31] A. Barber. (1997, March 11). Net's educational value questioned. USA Today, p. 4D. 